\title{
The importance of cerebrospinal fluid on neural cell proliferation in developing chick cerebral cortex Farhad Mashayekhi and Zivar Salehi*
}

\author{
Address: Department of Biology, Faculty of Sciences, Guilan University, Namjoo St., PoBox 1914, Rasht, Iran \\ Email: Zivar Salehi* - geneticzs@yahoo.co.uk \\ * Corresponding author
}

from 49th Annual Meeting of the Society for Research into Hydrocephalus and Spina Bifida

Barcelona, Spain, 29 June - 2 July 2005

Published: 30 December 2005

Cerebrospinal Fluid Research 2005, 2(SuppI I):S7 doi:10.1 I86/I743-8454-2-SI-S7

\section{Background}

A key event in the development of mammalian cerebral cortex is the generation and differentiation of neuronal population during embryonic life. Cerebrospinal fluid (CSF) is produced by the choroid plexuses within the ventricles of the brain. The CSF circulates in a regular manner after the ventricular system and the choroids plexuses have developed, and the foramina in the $4^{\text {th }}$ ventricle have opened to enable it to carry chemical information. CSF flows through the ventricular system passing over all regions of germinal activity. The central nervous system (CNS) of vertebrates originates from neuroepithelial cells located within the embryonic neural tube. Several mitogenic and trophic factors have been implicated in the processes of cortical cell proliferation and differentiation. These include fibroblast growth factor (FGF), insulin growth factor (IGF) and other neurotrophic factors. FGF promotes the proliferation of stem cells isolated from the brain and direct them toward specific fates. Stem cells are highly plastic, with their proliferation and differentiation potential dependent on different growth factor treatments. It was shown in vitro that brain-derived neurotrophic factor (BDNF) and glial-derived neurotrophic factor (GDNF) have positive effects in promoting neural progenitor cell differentiation towards the dopaminergic phenotype. In the subset of progenitor cells, FGF2 is necessary in early G1 to promote commitment to a subsequent cell cycle.

\section{Material and Methods}

In this study chick embryos were used to show the importance of CSF on neural cell proliferation in the developing cerebral cortex. The chick embryos were cannulated in situ with a fine capillary tube to drain CSF out of the ventricu- lar system. At the same time, BrdU was administered to the embryos. After surgery the embryos were incubated for another three days. All the CSF-drained and control embryos were collected, fixed in paraformaldehyde and cut on a microtome and stained with Methyl Green Pyronine and anti-BrdU antibody.

\section{Results}

Quantitative measurements showed that the thicknesses of the germinal epithelium and cerebral cortex in CSFdrained embryos were less than those in the control group at the same age ( $\mathrm{n}=20$ for each group). The number of cells produced in the germinal epithelium of CSF-drained embryos was decreased when compared to the normal group.

\section{Conclusion}

This study provides confirmatory evidence that CSF is important for neural cell proliferation 